\title{
Comportamento ingestivo de bovinos mantidos em pastos de Brachiaria brizantha cv. Xaraés manejado em diferentes alturas de pastejo $^{1}$
}

\section{Ingestive behavior of cattle kept in Brachiaria brizantha cv. Xaraés grass managed under different grazing heights}

\author{
Marco Aurélio Alves de Freitas Barbosa²; Letícia Maria Castro ${ }^{3 *}$ \\ Rondineli Pavezzi Barbero4; Vinicius Campachi Brito ${ }^{5}$; Renan Lucas Miorin ${ }^{5}$; \\ Rafael Mantegazza Saad ${ }^{5}$; Edson Luis de Azambuja Ribeiro ${ }^{6}$; \\ Valter Harry Bumbieris Junior ${ }^{7}$
}

\begin{abstract}
Resumo
O presente experimento foi conduzido para avaliar o efeito das alturas de pastejo sobre as atividades comportamentais diurnas de novilhos da raça Nelore na época das águas. A área experimental foi de 12 hectares divididos em piquetes de um hectare cada. Os tratamentos consistiram em quatro alturas de desfolha (15, 30, 45 e $60 \mathrm{~cm})$ em pastos de Brachiaria brizantha cv. Xaraés, com três repetições cada. O método de pastejo foi o de lotação contínua com taxa de lotação variável. Procedeu-se a coleta de material forrageiro nas parcelas experimentais e o mesmo foi direcionado ao laboratório para a separação dos componentes estruturais, pesagem e determinação de matéria seca, juntamente com o material colhido por simulação de pastejo. As variáveis: tempo de pastejo, tempo de ócio e tempo de ruminação foram avaliadas por 12 horas consecutivas nos dias 15 e 16 de fevereiro de 2011, considerando os turnos matutino e vespertino. O delineamento experimental adotado foi inteiramente casualizado. A altura do dossel forrageiro influenciou significativamente no tempo de pastejo diário e o tempo de ruminação, onde foi encontrado comportamento quadrático, em função da altura de desfolha. A taxa de bocados diminuiu em função das alturas estudadas. Já a composição bromatológica do material colhido por simulação de pastejo, não apresentou diferença entre os tratamentos. Pastos de capim Xaraés manejados próximos de $45 \mathrm{~cm}$ de altura proporcionam maior facilidade de apreensão de forragem pelos bovinos em pastejo. Palavras-chave: Ócio, simulação de pastejo, taxa de bocado, tempo de ruminação
\end{abstract}

\begin{abstract}
This experiment was conducted to evaluate the effect of grazing heights on daytime behavioral activities of Nellore beef cattle in the rainy season. The experimental area was 12 hectares divided into paddocks
\end{abstract}

\footnotetext{
${ }^{1}$ Parte de Dissertação de Mestrado em Ciência Animal, do segundo autor, Universidade Estadual de Londrina, UEL, Londrina, PR.

${ }^{2}$ Prof. Dr. do Dept ${ }^{\circ}$ de Zootecnia, UEL, Pesquisador Bolsista Fundação Araucária, Londrina, PR. E-mail: maafbarbosa@uel.br

${ }^{3}$ Zootecnista, M.e em Ciência Animal, Universidade Estadual de Londrina, UEL, Londrina, PR. E-mail: leticiacastro@zootecnista. com.br

${ }^{4}$ Zootecnista, Discente de Doutorado do Programa de Pós-graduação em Zootecnia da Faculdade de Ciências Agrárias e Veterinárias do Campus de Jaboticabal, UNESP, Jaboticabal, SP. E-mail: rondinelibarbero@zootecnista.com.br

${ }^{5}$ Zootecnistas, Discentes de Mestrado do Programa de Pós-graduação em Ciência Animal, UEL, Londrina, PR. E-mail: viniciuscampachi brito@hotmail.com; rlmiorin@zootecnista.com.br; rafaelsaad@zootecnista.com.br

${ }^{6}$ Prof. Dr. do Dept ${ }^{\circ}$ de Zootecnia, UEL, Pesquisador Bolsista Fundação Araucária, Londrina, PR. E-mail: elar@uel.br

${ }^{7}$ Prof. Dr. do Dept ${ }^{\circ}$ de Zootecnia, UEL, Londrina, PR. E-mail: dudabumbieris@hotmail.com

* Autor para correspondência
} 
of one hectare each. The treatments consisted of four defoliation heights $(15,30,45$ and $60 \mathrm{~cm})$ in pastures of Brachiaria brizantha cv. Xaraés with three replicates each. It was used the continuos grazing method, with variable stocking rate. Forage samples collected on the plots were sent to the laboratory for separation of the botanical components, weighing and determination of dry matter, with the material collected by simulated grazing. The variables: grazing time, idle time and ruminating time were evaluated for 12 consecutive hours on days 15 and 16 February 2011, considering the morning and afternoon periods. It was used a completely randomized design. The height of the canopy significantly influenced the daily grazing time and ruminating time, with a quadratic response as a function of time of defoliation. The bite rate decreased as a function of heights studied. However the chemical composition of the material collected by simulated grazing did not differ between treatments. Xaraés grass swards grazed at around $45 \mathrm{~cm}$ height provide greater ease of apprehension by grazing cattle.

Key words: Bit rate, idleness, rumination, simulation of grazing

\section{Introdução}

A compreensão dos hábitos e horários de pastejo dos bovinos é fundamental para melhorar e aperfeiçoar o aproveitamento das pastagens e elaborar estratégias de manejo dos pastos (ZANINE; SANTOS; FERREIRA, 2006). Quando a disponibilidade de forragem e o potencial animal não são limitantes, a qualidade da pastagem é definida pela produção do animal, estando diretamente relacionada com o consumo voluntário e disponibilidade dos nutrientes contidos na mesma (OLIVEIRA, 2006).

Os ruminantes podem alterar componentes do seu comportamento ingestivo com a finalidade de minimizar os efeitos de condições alimentares desfavoráveis, mas nem sempre conseguem impedir a queda do consumo diário de forragem (HODGSON, 1990).

Desta forma, pastagens com baixa qualidade e quantidade de forragem, principalmente com pouca disponibilidade de lâminas verdes e alta quantidade de colmos, são pouco consumidas, podendo haver seleção das partículas pastejadas, isso pode resultar em aumento do tempo total de pastejo, consequentemente, mudanças no comportamento ingestivo e baixo ganho de peso dos animais (SANTOS et al., 2009).

Pesquisas recentes com diversas gramíneas tropicais confirmaram que a estratégia de manejo baseada no monitoramento e controle da altura do pasto geram relações bastante consistentes entre as respostas da planta e dos animais e permite o entendimento dos efeitos das variações estruturais da pastagem sobre a produção, persistência da planta e o desempenho animal (FLORES et al., 2008).

Para o capim Xaraés, são raros os trabalhos enfocando o comportamento ingestivo de bovinos, principalmente sob lotação contínua e diferentes alturas de desfolha. Devido à importância que essa forrageira vem apresentando no cenário de produção de bovinos em pastagens, objetivouse com esse experimento avaliar o efeito de diferentes alturas de desfolha em pastos de capim Xaraés no comportamento animal na região do Arenito Caiuá.

\section{Material e Métodos}

O experimento aprovado pelo comitê de ética em experimentação animal da Universidade Estadual de Londrina sob registro $n^{\circ} 56 / 09$, foi realizado no município de Cidade Gaúcha, noroeste do Paraná, com $550 \mathrm{~m}$ de altitude. Segundo a classificação Köppen o clima da região é Cfa (verão quente e chuvoso, e inverno seco).

Os 12 hectares de área experimental, constituidos por Brachiaria brizantha cv. Xaraés com relevo levemente ondulado, foi dividido em 12 piquetes de igual tamanho, com três piquetes para cada tratamento: alturas de desfolha do dossel, 15, 30, 45 e $60 \mathrm{~cm}$, distribuídos aleatoriamente. 
A área utilizada para esse experimento foi estabelecida em fevereiro de 2009, sendo que em dezembro do mesmo ano, as alturas estudadas foram estabelecidas e mantidas até fevereiro de 2011, ocasião deste experimento.

Para a manutenção da altura do dossel foram utilizados por unidade experimental 3 bovinos machos ("testers"), da raça Nelore, com peso médio inicial de $340 \mathrm{~kg}$, castrados e vermifugados previamente ao experimento. Para a manutenção das alturas dos pastos animais adicionais foram empregados (MOTT; LUCAS, 1952), mas não foram utilizados no estudo, pois na ocasião do mesmo somente os "testers" estavam no pasto. A altura do dossel foi mensurada em 30 pontos aleatórios por piquete, com régua graduada, na curvatura das lâminas foliares superiores.

Foram coletadas quatro amostras reais de forragem e oito amostras visuais por piquete ao nível do solo com a utilização de quadrado amostrador (0,5 X 0,5m), realizando a quantificação da massa forrageira pelo método comparativo (HAYDOCK; SHAW, 1975).

As amostras reais foram levadas ao Laboratório de Alimentos e Nutrição Animal da Universidade Estadual de Londrina (LANA), onde se procedeu a separação das estruturas de acordo com os componentes; lâminas foliares verdes, colmos+bainhas e material senescente. O conteúdo de matéria seca (MS), fibra em detergente neutro (FDN), fibra em detergente ácido, proteína bruta (PB) e hemicelulose (HEMI) foram determinado utilizando-se metodologia adaptadas por Mizubuti et al. (2009). Ainda foram realizadas coletas de 20 amostras de forragem por piquete por simulação do pastejo após a observação do comportamento ingestivo.

Para o estudo da análise comportamental/ ingestivo, foi utilizado o método direto de observação visual (HUGHES; REID, 1951) dos animais devidamente identificados e adaptados a presença dos avaliadores. As observações foram realizadas por pessoas treinadas, nos dias 15 e 16 de fevereiro de 2011, nos horários compreendidos entre as 7h: 00 e $19 \mathrm{~h}: 00$ sendo 12 horas contínuas, totalizando 24 horas de observação. Não ocorreram precipitações durante os dias de observação e as temperaturas máxima e mínima foram de $28{ }^{\circ} \mathrm{C}$ e $16^{\circ} \mathrm{C}$ respectivamente.

A cada 10 minutos, foram feitos registros das atividades de pastejo, ruminação e ócio e após realizou-se o somatório para encontrar o tempo despendido nas atividades durante as horas de observação. O tempo de pastejo representa o período em que o animal está ativamente apreendendo ou selecionando forragem. O tempo de ruminação é considerado como o período em que o animal não está pastejando, entretanto, está mastigando o bolo alimentar retornado do rúmen, observado pelo movimento da boca do animal. O tempo de ócio indica o período em que o animal não está pastejando, nem tampouco ruminando.

Para a medida da taxa de bocados foi escolhido, aleatoriamente, um animal por piquete, e procederam-se estimativas visuais, medindose o tempo que o animal leva para completar 20 bocados de apreensão em intervalos de 10 minutos sempre que fosse verificada atividade de pastejo (FORBES; HODGSON, 1985). Após, este valor foi transformado para número de bocados por minuto. $\mathrm{O}$ ciclo de bocados foi realizado a cada hora mensurando-se o tempo que o animal mantinha-se de cabeça baixa e pastejando.

O delineamento experimental foi inteiramente casualizado, com três repetições por tratamento, e com um animal por piquete para taxa de bocados e ciclo de bocados. Para o tempo de pastejo, ruminação e ócio, cada animal foi considerado uma repetição. Foi realizada análise de variância e quando necessário aplicado procedimento de regressão. Para a avaliação das atividades em função do período (horas do dia), utilizou-se a comparação pelo teste Tukey $(\mathrm{P}<0,05)$. 


\section{Resultados e Discussão}

O tempo despendido nas atividades diárias de pastejo, ruminação e ócio variam de acordo com as horas do dia. Os dois períodos mais importantes de pastejo ocorrem ao amanhecer e ao entardecer e, entre estes períodos bem marcados, geralmente se produzem dois períodos curtos de pastejo, dependendo de fatores tais como: estação do ano, qualidade da pastagem, tempo, localização da água de bebida, entre outros (OLIVEIRA, 2010). A análise do tempo de pastejo, ruminação e ócio em função das 12 horas de observação (média dos dois dias de observação), estão expostas na Figura 1, separados para os diferentes tratamentos, os quais não apresentaram diferença para as variáveis em função dos horários analisados.

Em regiões mais quentes, deve-se considerar que o comportamento noturno é representativo nas atividades de bovinos em pastagens, principalmente o pastejo, fato que pode ter interferido nos resultados onde não houve diferença nas variáveis estudadas em função dos horários do dia. Brâncio et al. (2003), em revisão de literatura verificou que no verão os animais chegam a pastejar de duas a três horas no período noturno, evitando as horas quentes do dia.

Conforme demonstrado na Figura 2, o tempo despendido diariamente nas atividades de pastejo e ócio $(\mathrm{P}<0,05)$ apresentaram comportamento quadrático em função das alturas dos pastos de capim Xaraés $(15,30,45$ e $60 \mathrm{~cm})$. O ponto de mínimo tempo de pastejo ocorreu na altura 46,9 $\mathrm{cm}$ e o ponto de máxima ruminação nos $36,2 \mathrm{~cm}$ de altura de desfolha.

Bovinos em pastagens cultivadas despendem de 4 a 12 horas por dia para pastejo (BRÂNCIO et al.,
2003; SILVA et al., 2010) dependendo da estrutura da pastagem e das condições meteorológicas. Nesse experimento, o maior tempo de pastejo $(8,95 \mathrm{~h})$ foi encontrado na menor altura pretendida de desfolha, o que corrobora com o supracitado, estando dentro deste intervalo.

Em pastos manejados mais altos ou com maior massa de forragem, é comum a redução do tempo despendido para o pastejo, pois a colheita de forragem é otimizada, permitindo aumento no tamanho do bocado e que o animal atinja níveis ótimos de ingestão (TREVISAN et al., 2004).

Porém, Gontijo Neto et al. (2006), afirmam que acima de uma determinada altura a ingestão de massa é reduzida, pois a baixa densidade de forragem e a alta dispersão das lâminas foliares nos estratos superiores ocasionam menor massa por bocado.

Portanto, alturas elevadas do dossel, podem afetar de forma negativa a ingestão de matéria seca pelo animal em decorrência da alteração na estrutura da pastagem. Quando a massa de bocado é prejudicada, o animal tenta compensar essa perda, com o aumento do tempo de pastejo, aumentando os ciclos de bocados. Até certo ponto os animais têm a capacidade de aumentar a taxa de bocados ou o tempo de pastejo.

Para apreender maior quantidade de forragem em um pasto com estrutura de difícil apreensão (muito alto ou muito baixo), porém, o gasto energético do animal pode não compensar o gasto de energia para colher a forragem, ocorrendo assim, queda no desempenho (ZANINE; SANTOS; FERREIRA, 2006). Nesse experimento, o ciclo de bocados não apresentou influência das alturas de desfolha, sendo sua média total de 21,1 minutos por ciclo. 


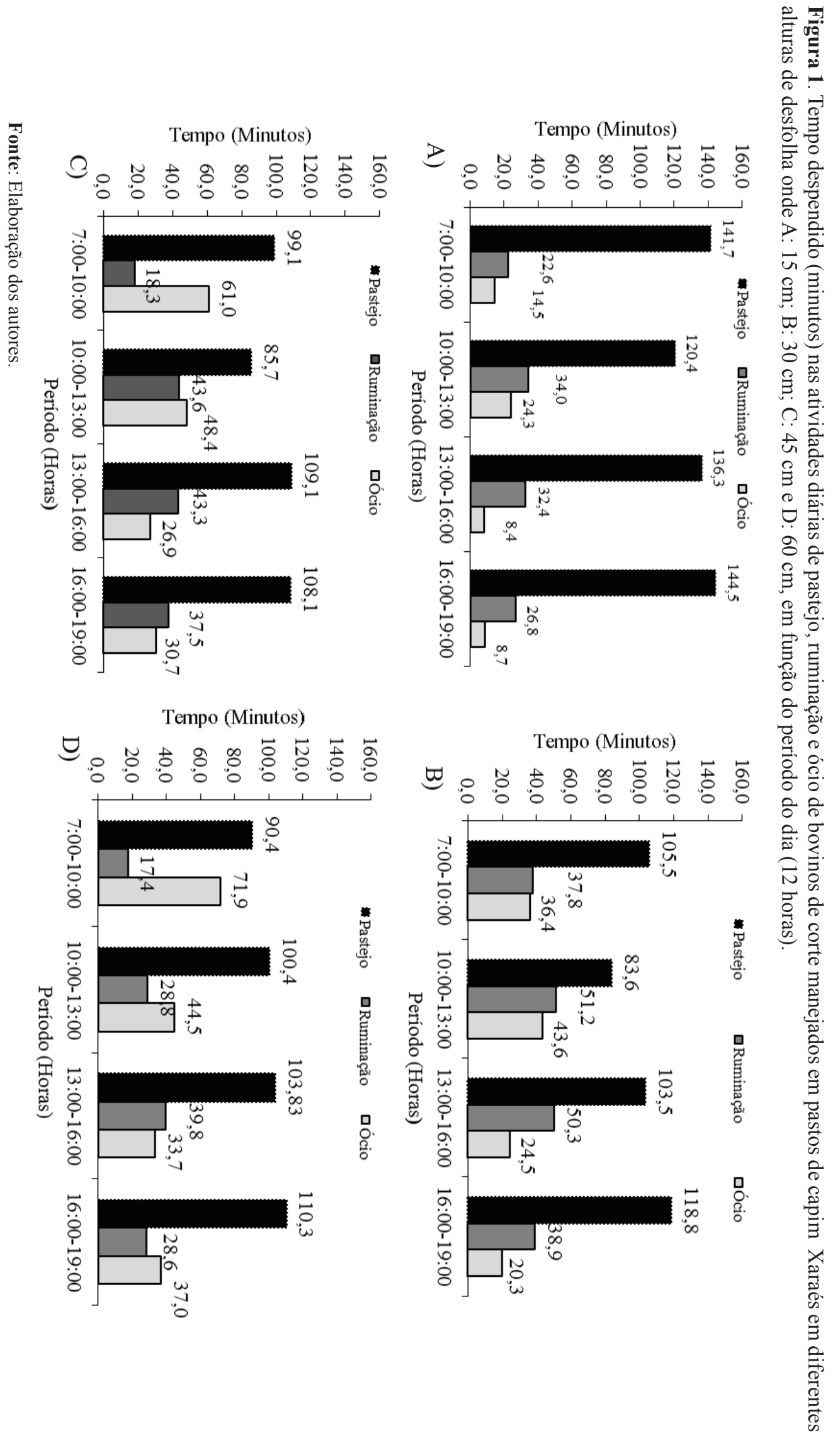


Figura 2. Tempo despendido (minutos) nas atividades diárias de pastejo, ruminação e ócio de bovinos de corte manejados em pastos de capim Xaraés em diferentes alturas de desfolha em um período de 12 horas.

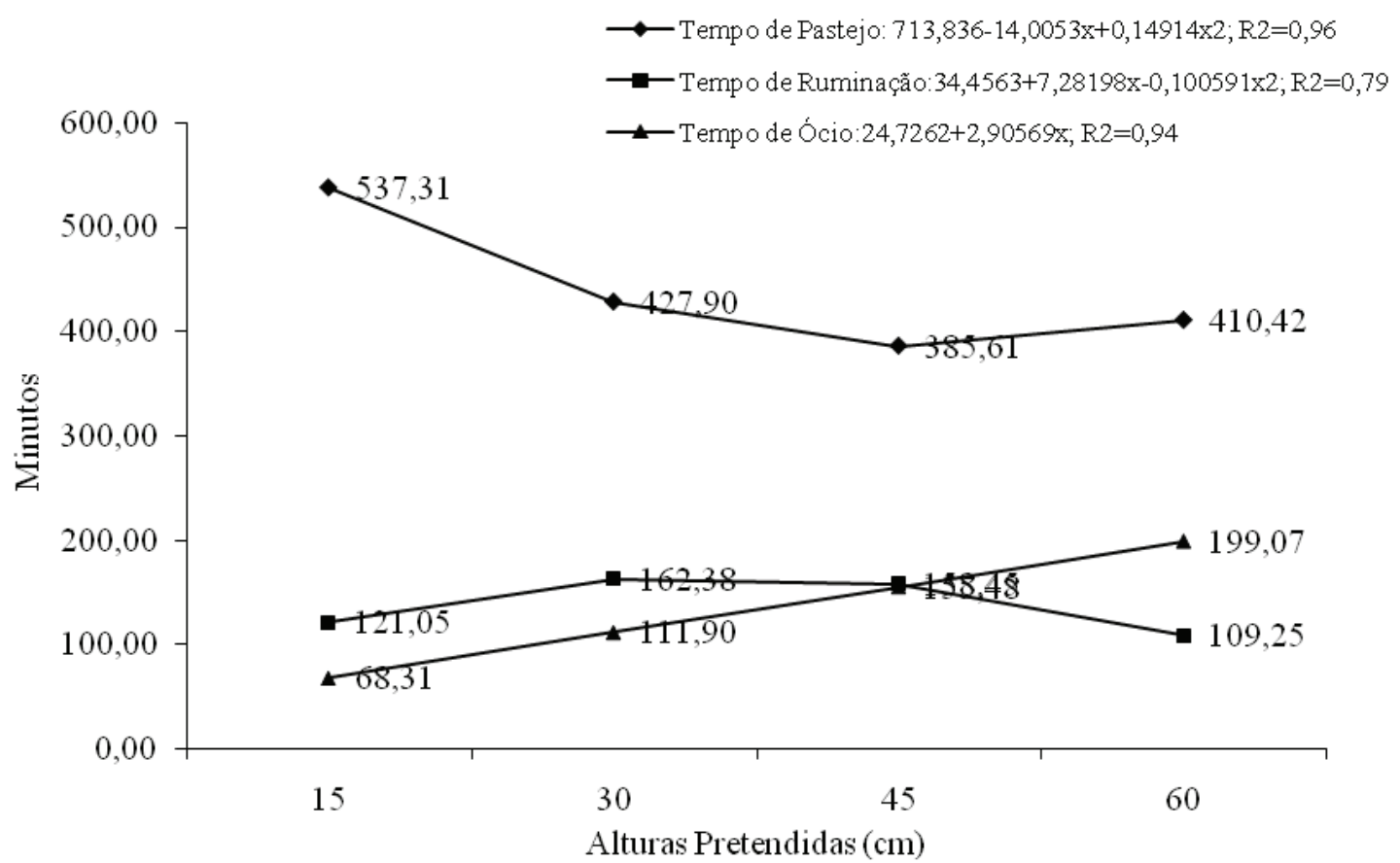

Fonte: Elaboração dos autores.

A taxa de bocados (Figura 3) apresentou de desfolha e seu ponto de máxima foi em 14,05 cm comportamento quadrático em função das alturas de altura.

Figura 3. Taxa de bocados de bovinos de corte manejados em pastos de capim Xaraés em diferentes alturas de desfolha.

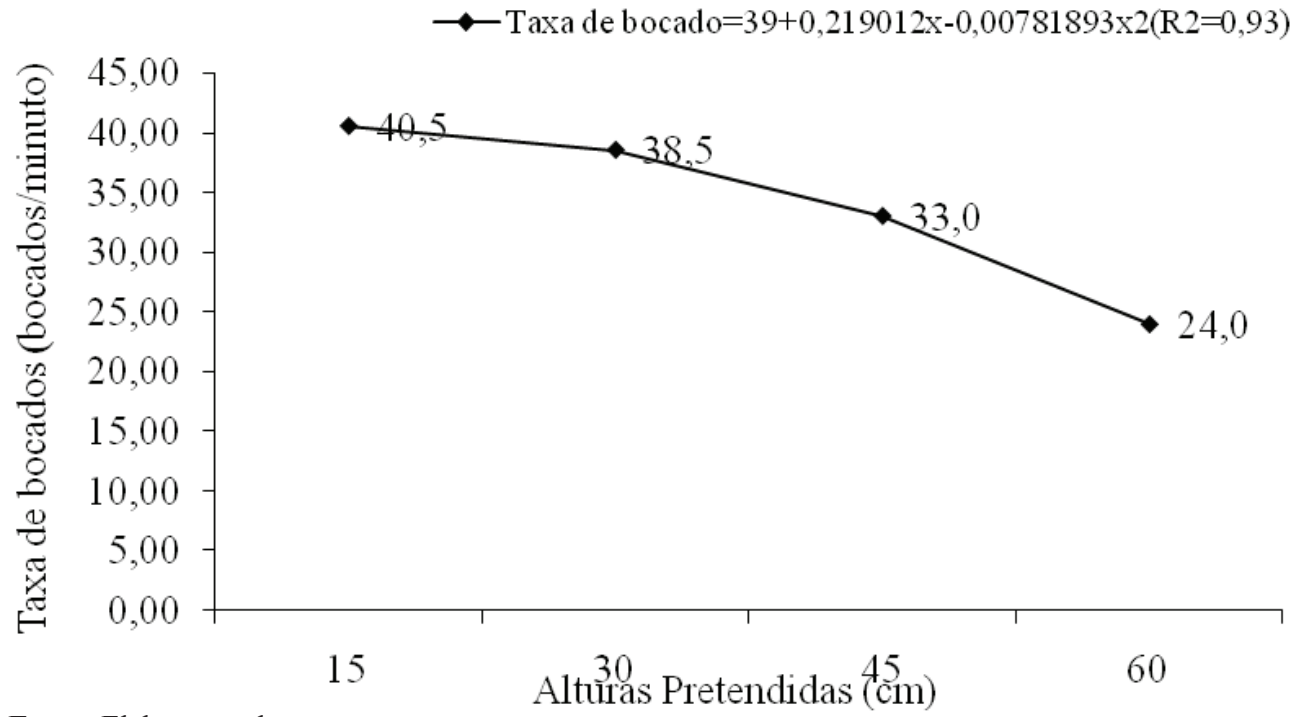

Fonte: Elaboração dos autores. 
Sarmento (2003) observou que a taxa de bocado varia em função da altura do pasto, avaliando o comportamento ingestivo de novilhas das raças Nelore e Canchim em pastagens de capim Marandu com alturas variando entre 10 e $40 \mathrm{~cm}$, sendo que na altura de $30 \mathrm{~cm}$ o valor foi de 23,8 bocados por minuto. Já para as alturas 10 e $40 \mathrm{~cm}$, os valores foram de 46,3 a 17,5 bocados/minutos respectivamente.

Uma vez que a taxa de bocado permite estimar a facilidade com que o animal seleciona e apreende a forrageira (FLORES et al., 2008), provavelmente os animais nos pastos manejados a $15 \mathrm{~cm}$ tiveram maior dificuldade de seleção e colheita da forragem.

A composição do material coletado por simulação de pastejo (Tabela 1) em função das alturas de desfolha não apresentou diferença significativa para nenhum dos parâmetros bromatológicos avaliados.

Esperava-se que, se tratando do período favorável do ano e de estruturas do estrato superior da pastagem, que o mesmo apresentasse maiores valores para $\mathrm{PB}$ e menores valores de FDN, contribuindo para uma dieta mais rica para os animais em pastejo.

Tabela 1. Composição bromatológica da coleta por simulação de pastejo de capim Xaraés em diferentes alturas de desfolha.

\begin{tabular}{cccccc}
\hline TRAT $(\mathrm{cm})$ & MS & PB & FDN & FDA & HEMI \\
\hline 15 & 37,65 & 61,3 & 708 & 331 & 377 \\
30 & 41,9 & 63,2 & 712 & 315 & 396 \\
45 & 36,6 & 67,7 & 705 & 327 & 378 \\
60 & 40,26 & 66,2 & 717 & 341 & 376 \\
\hline Média Geral & $39,11 \pm 10,3$ & $64,6 \pm 0,93$ & $711 \pm 3,97$ & $329 \pm 4,24$ & $381,9 \pm 2,87$ \\
\hline CV $\%$ & 10,2 & 9,1 & 3,3 & 6,5 & 7,1 \\
\hline Signif. & NS & NS & NS & NS & NS \\
\hline
\end{tabular}

Valores expressos em g.kg-1 de MS exceto a mesma, expressa em \% $\mathrm{NS}=$ não significativo $(\mathrm{P}>0,05)$

Fonte: Elaboração dos autores.

O material selecionado pelos animais em todos os tratamentos compunha-se basicamente de lâminas foliares. Como não foi encontrada diferença entre a qualidade da forragem selecionada, acreditase que a quantidade de material ingerido seria o responsável por melhores desempenhos em maiores alturas de pastejo (MODESTO et al., 2004).

\section{Conclusões}

A altura do dossel forrageiro em pastos de capim Xaraés influenciou o tempo de pastejo diário, onde os menores valores foram encontrados na altura $46,95 \mathrm{~cm}$ e o tempo de ruminação, na altura de 36,19 cm de desfolha. Pastos de capim Xaraés manejados próximos a $45 \mathrm{~cm}$ de altura proporcionam maior facilidade de apreensão de forragem pelos bovinos em pastejo.

\section{Referências}

BRÂNCIO, P. A.; EUCLIDES, V. P. B.; NASCIMENTO JÚNIOR, FONSECA, D. M. da; ALMEIDA, R. G.; MACEDO, M. C. M.; BARBOSA, R. A. Avaliação de três cultivares de Panicum maximum Jacq. sob pastejo: comportamento ingestivo de bovinos. Revista Brasileira de Zootecnia, Viçosa, MG, v. 32, n. 5, p. 1045-1053, 2003.

FLORES, R. S.; EUCLIDES, V. P. B.; ABRÃO, M. P. C.; GALBEIRO, S.; DIFANTE, G. S.; BARBOSA, R. A. Desempenho animal, produção de forragem e características estruturais dos capins marandu e xaraés 
submetidos a intensidades de pastejo. Revista Brasileira de Zootecnia, Viçosa, MG, v. 37, n. 8, p. 1355-1365, 2008.

FORBES, T. D. A.; HODGSON, J. Comparative studies of the influence of sward conditions on the behavior of cows and sheep. Grass and Forage Science, Oxford, v. 40, n. 1, p. 69-77, 1985.

GONTIJO NETO, M. M.; EUCLIDES, V. P. B.; NASCIMENTO JUNIOR, D.; MIRANDA, L. F.; FONSECA, D. M.; OLIVEIRA, M. P. de. Consumo e tempo diário de pastejo por novilhos Nelore em pastagem de capim-tanzânia sob diferentes ofertas de forragem. Revista Brasileira de Zootecnia, Viçosa, MG, v. 35, n. 1, p.60-66, 2006.

HAYDOCK, K. P.; SHAW, N. H. The comparative yield method for estimating dry matter yield of pasture. Australian Journal of Experimental Agriculture and Animal Husbandry, Melbourne, v. 15, n. 76, p. 663-670, 1975.

HODGSON, J. Grazing management: science into practice. United Kingdom: Longman Scientific and Technical, Longman Group, 1990. 203 p.

HUGHES, G. P.; REID, D. Studies on the behavior of cattle and sheep in relation to utilization of grass. Journal of Agricultural Science, Cambridge, v. 41, n. 4, p. 350355, 1951.

MIZUBUTI, I. Y.; PINTO, A. P.; PEREIRA, E. S.; RAMOS, B. M. O. Métodos laboratoriais de avaliação de alimentos para animais. Londrina: EDUEL- Editora da Universidade Estadual de Londrina, 2009. v. 1, 228 p.

MODESTO, E. C.; TEIXEIRA, M. C.; ANDRADE, P. B.; BOZZI, R.; MOURA, A. A. A.; MORENO, G. M. B.; CASIMIRO, M. Comportamento de novilhas suplementadas a pasto no semi-árido nordestino. REUNIÃO ANUAL DA SOCIEDADE BRASILEIRA DE ZOOTECNIA, 51., 2004, Campo Grande. Anais... Campo Grande, MS: [s.n], 2004. CD-ROOM.

MOTT, G. O.; LUCAS, H. L. The designs conduct, and interpretation of grazing trials on cultivated and improved pastures. In: INTERNATIONAL GRASSLAND CONGRESS, 6., 1952, Pennsylvania. Proceedings... Pennsylvania: State College Press, 1952. p. 1380-1385.
OLIVEIRA, A. A. Efeito da temperatura de présecagem na digestibilidade e nos fracionamentos da proteina e do carboidrato em gramineas tropicais. 2006. Dissertação (Mestrado em Ciência Animal e Pastagens) - Universidade Federal de Mato Grosso do Sul, Campo Grande, MS.

OLIVEIRA, A. A. Parâmetros comportamentais e fisiológicos de vacas em lactação suplementadas com torta de girassol. 2010. Dissertação (Mestrado em Ciência Animal) Universidade Estadual de Londrina, Londrina.

SANTOS, E. R. S.; FONSECA, D. M.; EUCLIDES, V. P. B.; RIBEIRO JR, J. I. ; NASCIMENTO JUNIOR, D. do; MOREIRA, L. M. Produção de bovinos em pastagens de capim braquiária diferidas. Revista Brasileira de Zootecnia, Viçosa, MG, v. 38, n. 4, p. 635642, abr. 2009.

SARMENTO, D. O. L. Comportamento ingestivo de bovinos em pastos de capim- Marandu submetidos a regimes de lotação contínua. 2003. Dissertação (Mestrado em Zootecnia) - Escola Superior de Agricultura Luiz de Queiroz. Universidade de São Paulo, Piracicaba.

SILVA, R. R.; PRADO, I. N.; SILVA, F. F.; ALMEIDA, V. V. S.; SANTANA JUNIOR, H. A. de; QUEIROZ, A. C.; CARVAlho, G. G. P. de; BARRoso, D. S. Comportamento ingestivo diurno de novilhos Nelore recebendo níveis crescentes de suplementação em pastejo de capim-braquiária. Revista Brasileira de Zootecnia, Viçosa, MG, v. 39, n. 9, p. 2073-2080, 2010.

TREVISAN, N. B.; QUADROS, F. L. F.; SILVA, A. C. F. da; BANDINELLI, D. G.; MARTINS, C. E. N.; SIMÕES, L. F. C.; MAIXNER, A. R.; PIRES, D. R. F. Comportamento ingestivo de novilhos de corte em pastagem de aveia preta e azevém com níveis distintos de folhas verdes. Ciência Rural, Santa Maria, v. 34, n. 5, p. 1543-1548, 2004.

ZANINE, A. de M.; SANTOS, E. M.; FERREIRA, D. J. Tempo de pastejo, ócio, ruminação e taxa de bocadas de bovinos em pastagens de diferentes estruturas morfológicas. Revista Electrónica de Veterinaria, REDVET, v. 7, n. 1, p. 1-10, 2006. 